\title{
Prediction of intramuscular fat in live bulls using real-time ultrasound and image analysis*
}

\author{
P. Polák ${ }^{1,3}$, J. A. Mendizabal' , N.E. Blanco Roa ${ }^{1}$, E. Krupa ${ }^{1}$, \\ J. Huba ${ }^{1}$, D. Peškovičová ${ }^{1}$ and M. Oravcová ${ }^{1}$ \\ ${ }^{1}$ Slovak Agricultural Research Center - Research Institute for Animal Production \\ Hlohovská 2, 94992 Nitra, Slovakia \\ ${ }^{2}$ Public University of Navarra, Agricultural Production Engineering Department \\ Campus de Arrosadía, 31006 Pamplona, Spain
}

(Received 28 November 2006; revised version 26 November 2007; accepted 15 January 2008)

\begin{abstract}
Sonograms of Longissimus dorsi muscle (LDM) area were taken before slaughter on the last thoracic vertebra by an Aloka SSD-500. Three sonograms of each bull were taken with 60,65 and $70 \%$ ultrasound intensity. A digital image of the LDM area was obtained on the last thoracic vertebra. Intramuscular fat content was detected by an Infratec 1265 - Meat Analyzer. The grey value of the sonogram measured by computer image analysis significantly correlated with the content of IMF, $r=0.78$ for Slovak Simmental, and $r=0.60$ for Holstein bulls. Area proportion of marbling determined on images obtained by computer image analysis (MARB) correlated significantly with IMF, $r=0.65$. This correlation was only significant for Slovak Simmental bulls. The obtained results suggest that prediction of intramuscular fat in meat is possible using the technique of ultrasound and computer image analyses of live animals. Further investigation is needed to improve measurement precision and to validate applicability among a wide variety of cattle breeds.
\end{abstract}

KEY WORDS: cattle, intramuscular fat, ultrasound measurement, image analysis, marbling

\section{INTRODUCTION}

Intramuscular fat (IMF) content contributes significantly to aroma, tenderness and juiciness of meat after heat treatment (Smith et al., 1984; Savell et al., 1986). Determination of IMF by the classical extraction method, as well as the assessment

\footnotetext{
${ }^{*}$ Supported by the Ministry of Agriculture SR Research Program, No. 2006 UO 27/0910502/0910517 and the Ministry of Education Project for Bilateral Cooperation, No. SK-CZ-10606

${ }^{3}$ Corresponding author: e-mail: polak@scpv.sk
} 
of marbling degree, which is further subjected to operator variability, can only be performed after the animals are slaughtered. From a practical point of view these methods are both time-consuming and costly and they contribute less to genetic progress than if analysis were possible on live animals. It is also inconvenient to assess marbling degree in meat on the basis of a scale (e.g., USDA, 1989) used to classify carcasses commercially in the USA, Japan and elsewhere because of the marked subjectivity (human factor) of such assessments.

Several papers have dealt with assessing IMF content and marbling degree by ultrasound only or combined with computer image analysis (Newman, 1987; Wilson et al., 1993; Brethour, 1994; Park et al., 1994; Hassen et al., 2001). The results to date of different authors suggest that the method can also be used in practice. For instance, Brethour (1994) estimated IMF content by the method of ultrasound and computer image analysis in sets of 108 and 103 heads of cattle with a coefficient of determination of the model $\mathrm{R}^{2}=0.57$ and 0.53 . Similarly, Herring et al. (1988) correlated data detected by ultrasound in a set of 81 crosses of various cattle breeds (Angus, Simmental, Red Angus, Brahman and Hereford) with data obtained by chemical analysis in a laboratory, and with a marbling scale, finding correlations up to $r=0.75$. Wilson et al. (1993) and Izquierdo et al. (1996) found an $\mathrm{R}^{2}$ range from 0.44 to 0.70 for various prediction models. Hassen et al. (2001) found values of $\mathrm{R}^{2}$ ranging from 0.69 to 0.91 for various prediction models of IMF content in meat. Liu et al. (1993) and Gerrard et al. (1996) correlated the marbling degree detected subjectively by a group of classifiers with the IMF content determined chemically, and found highly significant correlations $r=0.92$ and $r=0.75$. Kuchida et al. (1998) estimated IMF content with an accuracy of $\mathrm{R}^{2}=0.91$ by use of ultrasound and computer image analyses. In later work, Kuchida et al. (2000) estimated crude fat content in $M$. longissimus dorsi from the ratio of fat area obtained by computer image analysis on the beef samples originating from two experimental stations. The equation for the regression of the crude fat content prediction had a regression coefficient of $\mathrm{R}^{2}=0.96$. Analysis of covariance showed that the effects of experiment stations on intercepts and slopes were not significant $(\mathrm{P}>0.10)$.

The objective of this work was to analyse the possibilities of predicting the content of intramuscular fat in LDM of Slovak Simmental and Holstein cattle breeds in vivo and/or post-mortem by means of ultrasound and computer image analyses.

\section{MATERIAL AND METHODS}

\section{Animals}

Thirty Holstein $(n=18)$ and Slovak Simmental $(n=12)$ bulls were used in the experiment. Calves, born in various herds in Slovakia, were moved to the ex- 
perimental facility at the age of approximately 20 days. In the period of milk nutrition they were fed milk replacer in an average dose of 101 a day, lucerne hay and feed mixture ad libitum until weaning at the age of 3 months. Calves were housed individually in hutches during the period of milk nutrition. Young bulls were housed in tying stalls and fed standard feed rations composed of lucerne hay, maize silage and concentrate mixture up to the time of slaughter. The animals were slaughtered at the experimental slaughterhouse at SARC Nitra at the age of about 15 months. The average liveweight and age of Holstein and Slovak Simmental bulls at slaughter were: $521 \pm 8.9 \mathrm{~kg}, 490 \pm 9.0 \mathrm{~kg}$ and $455 \pm 7.7$ and $470 \pm 3.6$ days, respectively.

The experiment was conducted in accordance with institutional guidelines for animal care and was approved by the responsible animal care group (Ministry of Agriculture, Slovak Republic).

\section{Ultrasound measurement}

Sonograms of Longissimus dorsi muscle (LDM) area were taken $10( \pm 3)$ days before slaughter. An Aloka SSD-500 echocamera with a UST-5871-5 probe ( $5 \mathrm{Mhz}, 64 \mathrm{~mm}$ ) was used. Approximately $20 \mathrm{~min}$ before measurement the sedative Rometar at a dose $0.25 \mathrm{ml}$ per $100 \mathrm{~kg}$ liveweight was applied to prevent possible errors caused by excessive movement of bulls during measurement. Scanning position was prepared by shaving the skin. Contact medium (acoustic gel or plant oil) was applied to enable the ultrasound waves to pass from the probe to the tissues of the experimental animal. The proper position of the probe was between the $13^{\text {th }}$ thoracic and $1^{\text {st }}$ lumbar vertebra, vertical to the spine. The contact

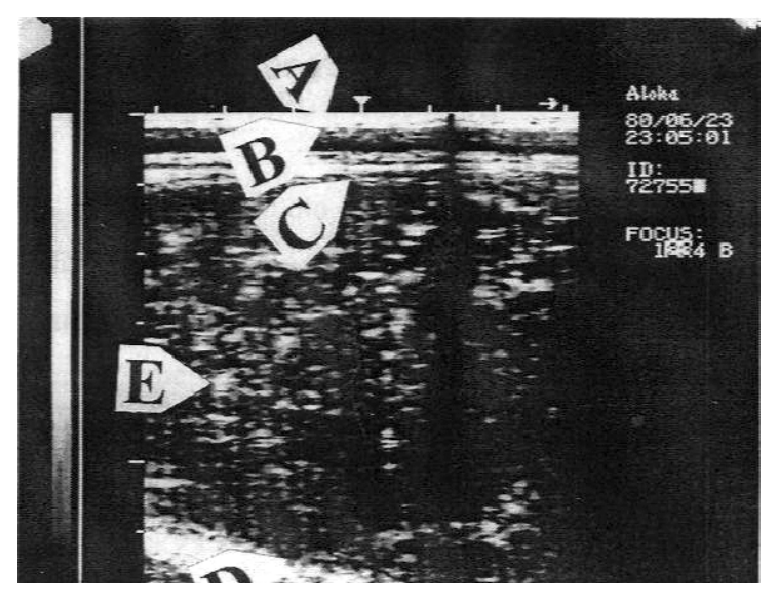

Figure 1. Description of sonogram. A-B Skin, B-C depth of subcutaneous fat, C-D depth of muscle, E marbling 
was projected immediately on the screen of the monitor; the picture of the transversal LDM area was displayed. Next, it was necessary to calibrate the picture in order to obtain appropriate brightness necessary for determination of tissues (subcutaneous fat, muscle, intramuscular fat and bone) (Figure 1). Three levels of ultrasound intensity $(60,65$ and $70 \%)$ were used to produce sonograms. The sonograms were printed using a Video Copy Processor Mitsubishi SSZ-305/305 $\mathrm{E}$ and digitalized by scanner.

\section{Digital imaging and laboratory analysis}

Dissection of right carcass side was performed $24 \mathrm{~h}$ after slaughter. Transversal cuts of each loin (Longsisimus dorsi muscle) were obtained from between the $13^{\text {th }}$ thoracic and $1^{\text {st }}$ lumbar vertebra, in the same place where the sonograms were taken. The surface of the cut was dried by filter paper and a digital image was taken by a Nikon $70 \mathrm{~F}$ camera .

A sample of LDM weighing approximately $150 \mathrm{~g}$ was taken for laboratory analysis. An Infratec 1265 - Meat Analyzer was used to determine intramuscular fat content.

\section{Computer image analysis of sonograms}

Computer image analysis was done in cooperation with the Department for Animal Production of the Public University of Navarra in Pamplona (Spain) using Optimas Version 6.5 (1996) software. Each ultrasound picture was analysed by two different methods, one covering the whole area, the other based on three smaller areas of interest (ROI):

\section{The whole LDM area}

The boundary line of the LDM area in the ultrasound picture was marked. The grey value of the marked area was measured. Gray value is a number from the interval 0-255 which represents the degree of colour of a pixel and is given by the software during computer processing for a particular pixel. Computer image analysis is based on digitalization of picture, i.e. the picture is changed into a set of points (pixels) that are identified by software according to their coordinates and threshold. The average threshold value of all points that are located in a particular analysed area of an ultrasound image is called the grey value or degree of greyness. The value of this measurement can vary from 0 to 255 degrees of greyness; 0 representing $100 \%$ black colouration and 255 represents $100 \%$ white colour of the image. In the sonogram of LDM, black colour represents muscular substance, and white colour represents intramuscular fat, subcutaneous fat, bones and blood capillaries. Grey value measurement was performed in all three ultrasound pic- 
tures of each animal. The obtained values were labelled INT-3 for $60 \%$, INT-2 for $65 \%$ and INT- 1 for $70 \%$ of ultrasound intensity, and used in the statistical analysis in this form.

2. The ROI method

Region of Interest (ROI) was measured according to Hassen et al. (1999) with some modification. In brief, three smaller areas of identical size $100 \times 100$ pixels (ROI) within the whole LDM area were selected and marked in each sonogram. ROI area was selected in such a way to be localized in all pictures in the same place, and to achieve the most homogeneous colouring and spreading in the given area. Too white colouring areas were sorted out because they corresponded to blood capillaries. Subsequently, the grey values for each ROI were measured. The average value of three ROI's of one sonogram was used in the statistical analysis. The average value of three ROI's of a sonogram obtained by intensity $70 \%$ was labelled ROI-1, for $65 \%$ ROI-2, and for $60 \%$ ROI-3.

\section{Computer image analysis of images}

The proportion of marbling of the total LDM area was measured on the digital images of the LDM transsection. As the digital images are in red, green and blue, we can change the tint of these colours to obtain the desired effect (contrast of colours) in the figure to make it possible for the programme to mark out the veining in marbling of muscle nearly automatically. After each operation we checked if the programme correctly carried out the marking, and we made adjustments if necessary. Processed images are shown in Figures 2 and 3. Data obtained in this way were used in the statistical analysis under the title MARB.

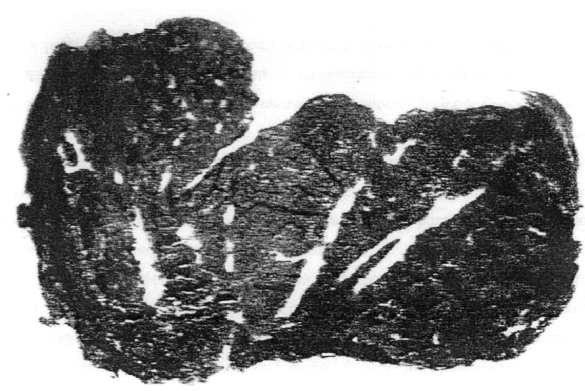

Figure 2. Digitalization and preparation of the image to assess marbling

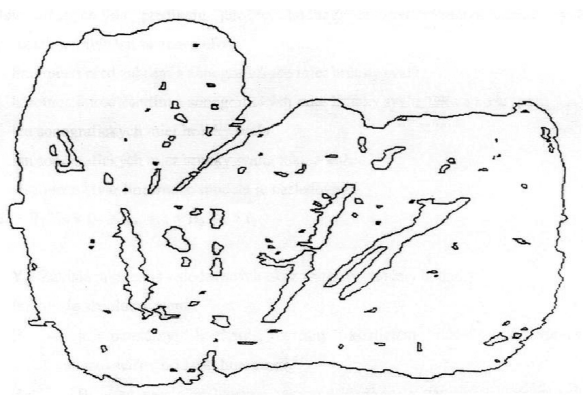

Figure 3. After the tint of colours on colour scale RGB (red, green and blue) was changed remained white colour only, i.e. marbling 


\section{Statistical analysis}

The basic statistics of measured values were calculated for both breeds. Statistical significance of differences between breeds were tested by the t-test. Pearson's coefficients of linear correlation among the content of intramuscular fat in LDM of bulls determined by INFRATEC and values assessed by computer image analysis in sonograms and digital pictures were calculated afterwards. Statistical analysis was calculated by procedures within the statistic package SAS (2002).

\section{RESULTS}

The basic statistics of the analysed variables and results of the t-test are given in Tables 1 and 2. Average IMF contents detected by INFRATEC for both breeds

Table 1. Basic statistics of weight before slaughter (WBS) and intramuscular fat content in Longissimus dorsi muscle (IMF) of Holstein (H) and Slovak Simmental bulls (S)

\begin{tabular}{lcccccc}
\hline Variable & Breed & Mean & SD & Minimum & Maximum & Differences \\
\hline \multirow{2}{*}{ WBS $^{1}, \mathrm{~kg}$} & $\mathrm{H}$ & 489.8 & 38.2 & 420.0 & 563.0 & $*$ \\
& $\mathrm{~S}$ & 523.0 & 32.4 & 468.0 & 560.0 & $*$ \\
$\mathrm{IMF}^{2}$ & $\mathrm{H}$ & 2.17 & 0.62 & 1.30 & 3.70 & \multirow{2}{*}{$\mathrm{NS}$} \\
& $\mathrm{S}$ & 2.39 & 0.58 & 1.60 & 3.60 & \\
\hline
\end{tabular}

${ }^{1}$ WBS-weight before slaughter, ${ }^{2} \mathrm{IMF}$ - intramuscular fat content, ${ }^{*} \mathrm{P}<0.05,{ }^{*} \mathrm{P}<0.01$, NS - non-significant

Table 2. Basic statistics of the average gray value obtained by computer image analysis of Longissimus dorsi muscle image and sonograms for Holstein (H) and Slovak Simmental (S) bulls

\begin{tabular}{lcrrrrc}
\hline Variable & Breed & Mean & \multicolumn{1}{c}{ SD } & Minimum & Maximum & Differences \\
\hline INT-1 & $\mathrm{H}$ & 56.11 & 11.06 & 38.00 & 78.00 & $* *$ \\
& $\mathrm{~S}$ & 44.33 & 8.20 & 38.00 & 68.00 & \\
INT-2 & $\mathrm{H}$ & 47.50 & 13.63 & 37.00 & 99.00 & $*$ \\
& $\mathrm{~S}$ & 38.83 & 2.40 & 36.00 & 43.00 & \\
INT-3 & $\mathrm{H}$ & 43.16 & 6.23 & 37.00 & 60.00 & $*$ \\
& $\mathrm{~S}$ & 37.41 & 1.97 & 35.00 & 40.00 & \\
ROI-1 & $\mathrm{H}$ & 60.60 & 18.49 & 38.10 & 97.45 & \multirow{2}{*}{ NS } \\
& $\mathrm{S}$ & 52.72 & 15.58 & 38.01 & 80.45 & \\
ROI-2 & $\mathrm{H}$ & 49.61 & 19.50 & 37.26 & 124.18 & $*$ \\
& $\mathrm{~S}$ & 39.50 & 3.20 & 34.77 & 44.25 & \\
ROI-3 & $\mathrm{H}$ & 44.29 & 10.51 & 35.83 & 69.25 & $*$ \\
& $\mathrm{~S}$ & 36.62 & 2.24 & 34.28 & 40.34 & \\
MARB & $\mathrm{H}$ & 2.37 & 1.35 & 0.54 & 4.43 & \multirow{2}{*}{ NS } \\
\hline
\end{tabular}

${ }^{*} \mathrm{P}<0.05,{ }^{*} \mathrm{P}<0.01$, - non-significant; average gray value obtained by computer image analysis of Longissimus dorsi muscle image (MARB); average gray value obtained by computer image analysis of LDM sonograms made by using by whole area and three ultrasound intensities $70 \%=\mathrm{INT}-1,65 \%=\mathrm{INT}-2$ and $60 \%=$ INT-3; average gray value obtained by computer image analysis of LDM region of interest $70 \%=\mathrm{ROI}-1,65 \%=\mathrm{ROI}-2$ and $60 \%=\mathrm{ROI}-3$; gray value is number from interval $0-55$ which represents degree of colour of pixel and is given by software during computer processing for particular pixel 
were similar: $2.17 \%$ for Holstein and 2.39\% Slovak Simmental breed. However, the differences between minimal and maximal values of intramuscular fat content were more marked $2.40 \%$ in Holstein as compared with 2\% in Slovak Simmental. The area proportions of marbling detected in digital images of LDM transsections by computer image analysis (MARB) were also similar in both breeds: $2.37 \%$ for Holstein and $2.55 \%$ for Slovak Simmental. The differences between breeds were highly significant for INT-1 and INT-3 and significant for INT-2. The differences between breeds were highly significant for ROI-3, significant for ROI-2 and nonsignificant for ROI-1.

Correlation coefficients among average gray values obtained by computer image analysis of Longissimus dorsi muscle sonograms using the whole area (INT) and region of interest (ROI) methods are given in Table 3. A relation between INT and ROI was observed. Correlation coefficients between INT-1 and ROI- 1 were 0.90 for $\mathrm{H}$ and 0.68 for S. Similarly, the correlation coefficients

Table 3. Correlation coefficients among average gray value obtained by computer image analysis of Longissimus dorsi muscle sonograms made by two methods for Holstein $(\mathrm{H})$ and Slovak Simmental (S) bulls

\begin{tabular}{lccccc}
\hline Variable & Breed & INT-1 & INT-2 & INT-3 & WBS \\
\hline \multirow{2}{*}{ ROI-1 } & $\mathrm{H}$ & $0.90^{* *}$ & 0.06 & 0.02 & 0.21 \\
& $\mathrm{~S}$ & $0.68^{*}$ & -0.15 & -0.41 & 0.23 \\
ROI-2 & $\mathrm{H}$ & 0.30 & $0.95^{* *}$ & $0.67^{* *}$ & 0.19 \\
& $\mathrm{~S}$ & $0.60^{*}$ & $0.77^{* *}$ & $0.59^{*}$ & -0.15 \\
ROI-3 & $\mathrm{H}$ & 0.27 & $0.57^{*}$ & $0.88^{* *}$ & 0.00 \\
& $\mathrm{~S}$ & -0.10 & $0.77^{* *}$ & $0.94^{* *}$ & 0.33 \\
WBS & $\mathrm{H}$ & 0.32 & 0.20 & 0.20 & \\
& $\mathrm{~S}$ & -0.48 & -0.12 & 0.29 & \\
\hline
\end{tabular}

$* \mathrm{P}<0.05, * * \mathrm{P}<0.01$; average gray value obtained by computer image analysis of LDM sonograms made by using by whole area and three ultrasound intensities $70 \%=\mathrm{INT}-1,65 \%=\mathrm{INT}-2$ and $60 \%=$ INT-3; average gray value obtained by computer image analysis of LDM region of interest $70 \%=$ ROI $-1,65 \%=$ ROI -2 and $60 \%=$ ROI -3

between INT-2 and ROI-2 were 0.95 for $\mathrm{H}$ and 0.77 for $\mathrm{S}$, the correlation coefficient between INT-3 and ROI-3 was 0.88 for $\mathrm{H}$ and 0.94 for S. Correlation coefficients between pairs of ROIs and INTs increased with increasing ultrasound intensity in the Slovak Simmental group. In Holstein bulls, the correlation coefficient between INT-2 and ROI-2 was the highest. This means that correlation coefficients between traits of INT's and ROI's were significant or highly significant in both breeds. Relationships between weight before slaughter (WBS) and ROI's and INT's of all intensities were nonsignificant in both of the breeds.

Correlation coefficients among IMF, MARB, INTs and ROIs for Holstein and Slovak Simmental bulls are in Table 4. Highly significant correlation 
Table 4. Correlation coefficients among intramuscular fat content, average gray value obtained by computer image analysis of Longissimus dorsi muscle image and sonograms for Holstein (H) and Slovak Simmental (S) bulls

\begin{tabular}{lccc}
\hline Variable & Breed & IMF & MARB \\
\hline \multirow{2}{*}{ MARB } & H & 0.36 & \\
& S & $0.65^{*}$ & \\
INT-1 & H & $0.60^{* *}$ & 0.35 \\
& S & $0.79^{* *}$ & $0.65^{*}$ \\
INT-2 & H & -0.00 & 0.00 \\
& S & 0.21 & 0.07 \\
INT-3 & H & -0.18 & -0.18 \\
& S & 0.06 & -0.05 \\
ROI-1 & H & $0.68^{* *}$ & 0.30 \\
& $\mathrm{~S}$ & 0.50 & $0.53^{*}$ \\
ROI-2 & $\mathrm{H}$ & 0.00 & -0.03 \\
& $\mathrm{~S}$ & 0.42 & $0.57^{*}$ \\
ROI-3 & $\mathrm{H}$ & -0.05 & -0.28 \\
& $\mathrm{~S}$ & -0.12 & -0.18 \\
WBS & $\mathrm{H}$ & 0.26 & -0.16 \\
& $\mathrm{~S}$ & -0.24 & 0.35 \\
\hline
\end{tabular}

${ }^{1}$ WBS - weight before slaughter; average gray value obtained by computer image analysis of Longissimus dorsi muscle image (MARB); average gray value obtained by computer image analysis of LDM sonograms made by using by whole area and three ultrasound intensities $70 \%=$ INT-1, 65 $\%=$ INT-2 and $60 \%=$ INT-3; average gray value obtained by computer image analysis of LDM region of interest $70 \%=$ ROI $-1,65 \%=$ ROI -2 and $60 \%=$ ROI $-3 ; * \mathrm{P}<0.05, * * \mathrm{P}<0.01$

coefficients ( $\mathrm{r}=0.60$ for Holstein and $\mathrm{r}=0.79$ for Slovak Simmental breeds) were found between IMF and INT-1. Correlations between IMF and INT-2 and INT-3 were nonsignificant. When INT-1, INT-2 and INT-3 were replaced by ROI-1, ROI2 and ROI-3 highly significant correlation coefficients between IMF and ROI-1 for the group of Holstein animals $(\mathrm{r}=0.68)$ were found. Correlation coefficients between IMF and ROI-1 in the group of Slovak Simmental bulls were nonsignificant $(\mathrm{r}=0.50)$. A significant correlation coefficient between IMF and MARB $(\mathrm{r}=0.65)$ for the group of Slovak Simmental bulls was found. In contrast, the correlation coefficient between IMF and MARB for Holstein bulls was nonsignificant.

\section{DISCUSSION}

The correlation coefficients between ultrasound data and IMF obtained in the present work are comparable to the results published by Brethour (1994), $\mathrm{r}=0.27$ $0.55\left(\mathrm{R}^{2}=0.53-0.57\right)$, Izquierdo et al. (1996), $\mathrm{r}=0.60\left(\mathrm{R}^{2}=0.50-0.59\right)$ and Hassen et al. (2001), $\mathrm{r}=0.33-0.53\left(\mathrm{R}^{2}=0.69\right)$. Liu et al. (1993) and Herring et al. (1998) 
mentioned higher correlation coefficients. There also exist works with markedly lower correlation coefficients between ultrasound data and IMF, e.g., Kriese (1996), $\mathrm{r}=0.34$.

There can be various causes of differences in results among the authors. According to Houghton and Turlington (1992) results obtained by this method depend first of all on the quality of obtained sonograms. Hassen et al. (2001) point out that the quality of sonograms depends on the type of ultrasound apparatus and process of sonogram digitalization used. Rantanen and Ewing (1981) and Herring and Bjorton (1985) reported that the type and frequency of the used probe have great influence on the quality of ultrasound images. Also movement of animals while taking the pictures (Brethour, 1990) and experience of the operator (McLaren et al., 1991) are factors that are decisive for the quality of sonograms. Another important factor is correct interpretation of sonograms with the aim to correctly distinguish the tissues (subcutaneous fat, muscle, blood capillaries, intramuscular fat and bones) for subsequent application of computer image analysis (Amin et al., 1995; Kriese, 1996).

Our results indicate that the statistical significance of the correlation between IMF in LDM and grey value of images depends to a large extent on content of IMF in meat of animals of studied breeds and the magnitude of the difference between its minimum and maximum values. The higher the mean relative content of IMF and the larger the difference between minimum and maximum values of IMF in a given population, the higher are the detected correlations and vice versa.

When average values of IMF in meat of various breeds were compared with American breeds, the IMF content was 5.28\% (Gerrard et al., 1996); with Japanese breeds the IMF content was 5\% for Japanese Black and 8\% for Japanese Shorthorn (Kuchida et al., 1992). Values found with European breeds, including Slovak and Spanish breeds, are markedly lower. For instance, with Asturiana Spanish cattle the IMF content was 2.2\% (Goñi et al., 1999), and with Slovak Simmental, 1.5\% (Zaujec et al., 2003). Ender et al. (1997) reported an average value of IMF content of $2.2 \%$ in European breeds, with the most common span of minimum (1.2\%) and maximum $(3.2 \%)$ values being $2 \%$. The actual span found in IMF content values in the presented experiment (1.3 to $3.7 \%$ ) is very small compared with values of American and Japanese breeds that showed markedly larger spans (from 3 to $10 \%$ ). This could partly explain why the correlation coefficients reported in this work were lower than those reported by American and Japanese authors.

A further source of variability in results could be the use of different methods. While in the study of Hassen et al. (1999) sonograms were taken longitudinally, measuring the grey value in the area of one ROI, in this study sonograms were taken transversally, measuring the grey value in three ROI's and using their average in statistical analysis. Considering that muscular fibres and most blood capillaries are placed along the muscle (the largest amount of intramuscular fat is con- 
centrated around the capillaries), the transverse section of the muscle should be more representative than a longitudinal one. From this point of view, the results presented in this study should be more objective.

\section{CONCLUSIONS}

The results show that the degrees of sound intensities of 60 and $65 \%$ out of the total volume increase in the echocamera are insufficient for the prediction of IMF content in meat; therefore lower intensities than these cannot be recommended. On the other hand, with a sound intensity of $70 \%$ out of total volume increase the detected correlations show acceptable ability to predict IMF content. It is probable that higher correlation coefficients could be obtained by using a sound intensity higher than $70 \%$. A certain proportional tendency could be seen: the higher the used sound intensity, the higher the predictive ability obtained, and vice versa; therefore it is necessary to continue research with intensities higher than $70 \%$ to definitively confirm this fact. On the basis of the obtained results it can be stated that the possibility of predicting IMF content in beef in vivo by means of ultrasound measurement (ROI-1) and computer image analysis exists. Further studies are needed to improve measurement precision and to validate the applicability of this method on a wider scale among cattle breeds.

\section{REFERENCES}

Amin V., Wilson D.E., Rouse G.H., 1995. An Ultrasound Image Analysis Software for Beef Quality Research. Beef Research Report. A.S Leaflet RI 437, Iowa State University, Ames, pp. 41-47

Blanco Roa N.E., Huba J., Polák P., Hetényi L., Zaujec K., 2002. Predikcia mramorovania svalu longissimus dorsi býkov ultrasonografickou metódou. J. Farm Anim. Sci. 35, 113-120

Brethour J.R., 1990. Relationship of ultrasound speckle to marbling score in cattle. J. Anim. Sci. 68, 2603-2613

Brethour J.R., 1994. Estimating marbling score in live cattle from ultrasound images using pattern recognition and neural network procedures. J. Anim. Sci. 72, 1425-1432

Ender K., 1997. Künftige Qualitätsanforderungen an Rindfleisch. In: R. Kolesár (Editor). Proceedings of an International Symposium on Actual and Perspekctiv Tasks in Farm Animal Breeding. RIAP Nitra (Slovakia), Part 2, pp. 27-33

Gerrard D.E., Gao X., Tan J., 1996. Beef marbling and color score determination by image processing. J. Food Sci. 61, 145-158

Goñi V., Mendizábal J.A., Beriain M.J., Alberti P., Arana A., Eguinoa P., Purroy A., 1999. Marbrure de la viande de veaux de sept races á viande espagnoles determineé par Analyse d' Image. Renc. Rech. Ruminants 6, 278

Hassen A., Wilson D.E., Amin V.R., Rouse G.H., Hays C.L., 2001. Predicting percentage of intramuscular fat using two types of real-time ultrasound equipment. J. Anim. Sci. 79, 11-18 
Hassen A., Wilson D.E., Amin V.R., Rouse G.H., 1999. Repeatability of ultrasound-predicted percentage of intramuscular fat in feedlot cattle. J. Anim. Sci. 6, 1335-1340

Herring D.S., Bjorton G., 1985. Physics, facts, and artifacts of diagnostic ultrasound. Vet. Clin. N. Amer. - Small Anim. 15, 1107-1122

Herring W.O., Kriese L.A., Bertrand J.K., Crouch J., 1988. Comparison of four real-time ultrasound systems that predict intramuscular fat in beef cattle. J. Anim. Sci. 76, 364-370

Houghton P.L., Turlington L.M., 1992. Application of ultrasound for feeding and finishing animal: A review. J. Anim. Sci. 70, 930-941

Izquierdo M., Amin V., Wilson D.E., Rouse G.H., 1996. Models to predict intramuscular fat percentage in live beef animals using real - time ultrasound and image parameters: Report on Data From 19911994 Beef Research Report, Iowa State University, Ames. A.S. Leaflet R 1324, pp. 3-6

Kriese L., 1996 Ultrasound past pitfalls and present promise. In: Proceeding of the Beef Improvemet Federation Research Symposium and Animal Meeting, Birmingham (USA), pp. 73-87

Kuchida K., Konishi K., Suzuki M., Miyoshi S., 1998. Prediction of the crude fat contents in ribeye muscle of beef using the fat area ratio calculated by computer image analysis. Anim. Sci. Technol. (Jpn.) 69, 655-658

Kuchida K., Kono S., Konishi K., Van Vleck L.D., Suzuki M., Miyoshi S., 2000. Prediction of crude fat content of longissimus muscle of beef using the ratio of fat area calculated from computer image analysis: Comparison of regression equations for prediction using different -input devices at different stations. J. Anim. Sci. 78, 799-803

Kuchida K., Yamaki K., Yamagishi T., Mizuma Y., 1992. Evaluation of meat quality in Japanese beef cattle by computer image analysis. Anim. Sci. Technol. (Jpn.) 63, 121-128

Liu Y., Aneshanslej D.J., Stouffer J.R., 1993. Autocorrelation of ultrasound speckle and its relationship to beef marbling. Tras. Amer. Soc. Agr. Eng. 36, 971-980

Mc Laren D.G., Novakofski J., Parret D.F., Lo L.L., Singh S.D., Neuman K.R., Mc Keith F.K., 1991. A study of operator effects on ultrasonic measures of fat depth and longissimus muscle area in cattle, sheep and ping. J. Anim. Sci. 69, 54-66

Newman P.D., 1987 The use of video image analysis for quantitative measurement of visible fat and lean in meat: Part 3 - Lipid content variation in comercial processing beef and its prediction by image analysis. Meat Sci. 19, 129-137

Optimas, 1996. User Guide and Technical Reference, Version 6. Optimas Corporation, Bothell. Washington, DC

Park B., Wittaker A.D., Miller R.K., Hale D.S., 1994. Predicting intramuscular fat in beef -Longissimus dorsi muscle for speed of sound. J. Anim. Sci. 72, 109-116

Rantanen N.W., Edwing R.L., 1981. Principles of ultrasound application in animals. Vet. Radiol. 22, 196-203

SAS, 2002. Version 8.2, SAS Institute Inc. Cary, NC

Savell J.W., Cross H.R., Smith G.C., 1986. Percentage ether extractable fat and moisture content of beef longissimus muscle as related to USDA marbling score. J. Food Sci. 51, 838-840

Smith G.C., Carpenter Z.L., Cross H.R., Murphey C.E., Abraham H.C., Savell J.W., David G.W., Berry B.W., Parrish F.C., 1984. Relationship of USDA marbling groups to palatability of cooked beef. J. Food Qual. 7, 289-308

USDA, 1989. Official United State Standards for Grades of Beef Carcasses. Agricultural Marketing Service. U.S. Department of Agriculture. Washington, DC

Wilson D.E., Zhang H., Rouse G.H., Izquierdo M., Duello D.A., Hinz P.N., 1993. Using real - time ultrasound to predict intramuscular fat in the longissimus dorsi of live beef animals. Beef Research Report, Iowa State University, Ames. A.S. Leaflet R 1017, pp. 29-31

Zaujec K., Mojto J., Novotná K., 2003. Beef marbling level of different slaughter category of cattle (in Slovak). J. Farm Anim. Sci. 36, 119-125 